\title{
SIMULATION OF HEAT TRANSFER BY COOLING CHANNELS IN LTCC SUBSTRATE
}

\author{
Tomas GIRASEK ${ }^{*}$, Alena PIETRIKOVA*, Tilo WELKER ${ }^{*}$, Jens MÜLLER ${ }^{* *}$ \\ *Department of Technologies in Electronics, Faculty of Electrical Engineering and Informatics, \\ Technical University of Košice, Letná 9, 04200 Košice, Slovak Republic, Tel.: +421 55602 3014, E-mail: tomas.girasek@tuke.sk \\ **Electronics Technology Group, Technical University of Ilmenau, Gustav-Kirchhoff-Str.1, Ilmenau, 98693, Germany
}

\begin{abstract}
The thermal resistance, flow analysis, pressure drop and distribution of coolant inside multilayer LTCC (Low Temperature Co-fired Ceramics) substrate are detailed investigated in this paper. For this reason four various structures of internal channels in the multilayer LTCC substrates were designed and simulated. The simulation $3 D$ model consist of 6 LTCC of DuPont $951^{\circledR}$ layer with cooling microchannel in middle of substrate, power chips paced on top of LTCC and silver sintered joints under power chips. The impact of the structure of channels, volume flow and power loss of die was simulated, calculated and analyzed by using the simulation software Mentor Graphics FloEFD ${ }^{T M}$. The structure and size of channels have the significant impact on thermal resistance, pressure of coolant as well as the effectivity of cooling power components which can be placed on LTCC substrate. The thermal resistance was calculated from the temperature gradient among chip junction, the inlet fluid and the thermal load of chip. Optimizing and comparison of cooling channels structure inside LTCC substrates and analyzing the effect of volume flow for achieving the least thermal resistance of LTCC multilayer substrate is the main contribution of this paper.
\end{abstract}

Keywords: thermal simulation, thermal resistance, LTCC, cooling channels

\section{INTRODUCTION}

Nowadays is thermal management of electronic devices serious problem because of electronics miniaturization, high performance and high reliability. The amount of the heat flux is growing up by the improvement of chip integration, package density, small size, layer quality, high frequency and high power loss in small area $[1,2]$. The electronic devices used in power electronic applications have to work properly in a very wide temperature range up to $200^{\circ} \mathrm{C}$. High temperature changes generate large thermal stress that affects power devices reliability. Therefore the thermal analysis has been carried out at the preliminary stage of the manufacturing and design.

LTCC technology with embedded microchannel is novel application in automotive technology, avionics, biology, military and telecommunication applications where the heat dissipation and high frequency property are mainly required $[3,4,9]$. In the recent years the interest of the fluidic structures in LTCC is growing [2, 5, 9]. LTCC is well suited as package solution for harsh environments due to their inherent features such as excellent thermal and chemical stability, hermeticity, simple 3D structuration, matching of thermal expansion coefficient with silicon and possibility of different fluidic and electrical component integration inside one ceramic substrate $[3,10$, 11]. These interesting features can be used in different applications of industry, where is the necessity to cooling the devices by the coolant inside the microfluidic system $[1,2,4,5,7,9]$.

LTCC technology via small channels allows a promising solution for improving heat dissipation and for decreasing the limited high temperature from the power chip. However, the poor thermal conductivity (which is about 3 to $5 \mathrm{Wm}^{-1} \mathrm{~K}^{-1}$ ) limits their application for power electronic $[5,6]$. For this reason the poor thermal conductivity of LTCC has to be improved by a coolant, which is pumped through the fluidic channels inside the
LTCC devices [1, 3, 4, 6, 7, 8]. Integrated microchannel cooling system in LTCC substrate can decrease the additional temperature more than $80 \%$ [20]. The main advantage of LTCC substrate with integrated liquid cooling system is the heat dissipation from the point of the thermal source. For this reason these devices provide an excellent thermal performance for high power application with theoretical heat flux of 1000 W.cm ${ }^{-2}[1,4]$. Moreover the LTCC devices may not be bonded to a metal heat sink, which reduces material, weight and volume that means less process' steps within production.

This paper presents the comparison of thermal resistance, flow analysis and distribution of coolant in four various structures of internal channels in multilayer LTCC substrates. The dimensions and structure of microchannel has been chosen and modified to obtain better cooling performance for different working conditions. The heat transfer behaviors was characterized by the decrease of maximum working temperature, thermal resistance of substrate, temperature distribution, fluid pressure and flow velocity fields. Presented designs ware simulated by using the simulation software Mentor Graphic FloEFD ${ }^{\mathrm{TM}}$.

The main motivation for creation of this work was analysis and calculation of heat transfer, impact of channels' shape to pressure drop that is expressed by particular numerical results oriented to reducing the thermal resistance. Moreover in power applications is necessary to know the impact of the thermal load of first chip on the temperature of the second chip. The presented results will be helpful for the optimization of design the cooling microchannel structure in future work with the real multilayer structures for high power devices.

\section{INTERNAL CHANNELS STRUCTURE}

The used material for the experiments was a commercially available LTCC green tape DuPont $951^{\circledR}$ with thermal conductivity $3.3 \mathrm{Wm}^{-1} \mathrm{~K}^{-1}$. The created 3D model consists of 6 layers of DuPont $951^{\circledR}$ with $0.214 \mathrm{~mm}$ 
thickness and $\mathrm{SiC}$ chip with thermal conductivity $120 \mathrm{Wm}^{-1} \mathrm{~K}^{-1}$ and dimension $10 \times 10 \times 1 \mathrm{~mm}^{3}$ such as the thermal load generator. Thickness of the LTCC substrate was $1.2 \mathrm{~mm}$. The fluidic channel integrated in the third layer from the top of the 3D model has the cross sectional area of $2 \times 0.214 \mathrm{~mm}^{2}$ for the shape $\# 1, \# 2, \# 3$ and $10 \mathrm{x}$ $0.214 \mathrm{~mm}^{2}$ for the shape \#4. All dimensions of the structures are listed in the Table 1. Multilayer structure of LTCC substrate is shown in the Fig. 1.

Table 1 Structures dimensions

\begin{tabular}{|c|c|c|c|c|}
\hline Structures & $\# 1$ & $\# 2$ & $\# 3$ & $\# 4$ \\
\hline $\begin{array}{l}\text { Width of } \\
\text { channel }[\mathrm{mm}]\end{array}$ & 2 & 2 & 2 & 10 \\
\hline $\begin{array}{l}\text { Length of } \\
\text { channel [mm] }\end{array}$ & 105 & 150 & $3 \times 48$ & 48 \\
\hline $\begin{array}{l}\text { Thickness of } \\
\text { channel [mm] }\end{array}$ & 0.214 & 0.214 & 0.214 & 0.214 \\
\hline $\begin{array}{l}\text { Area under the } \\
\text { chip }\left[\mathrm{mm}^{2}\right]\end{array}$ & 71 & 60 & 60 & 100 \\
\hline $\begin{array}{l}\text { Inlet hole } \\
\text { dimension [mm] }\end{array}$ & 2 & 2 & 2 & 2 \\
\hline $\begin{array}{l}\text { Outlet hole } \\
\text { dimension }[\mathrm{mm}]\end{array}$ & 2 & 2 & 2 & 2 \\
\hline
\end{tabular}

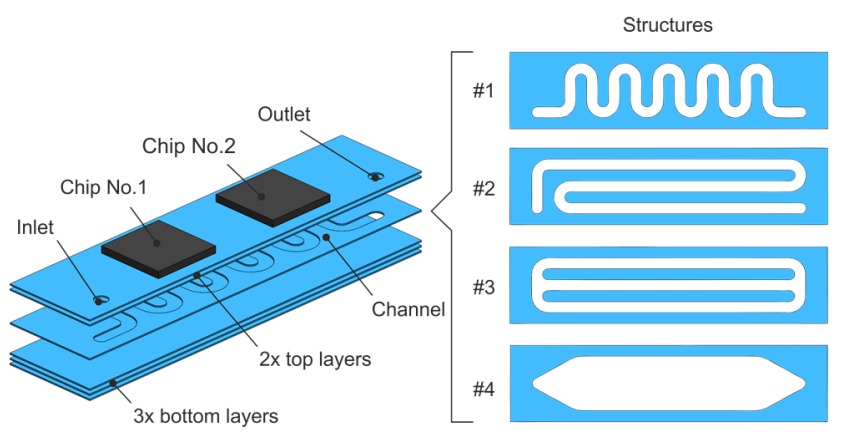

Fig. 1 Multilayer structure of LTCC substrate with microchannels

Between the power chips and LTCC substrate is the layer of silver pads and the layer of silver sintered joint. The dimension of both layers is $10 \times 10 \mathrm{~mm}^{2}$ and the thickness is $10 \mu \mathrm{m}$. Thermal conductivity of silver sintered joints are $140 \mathrm{~W} \cdot \mathrm{m}^{-1} \mathrm{~K}^{-1}$ and for silver pads are $360 \mathrm{~W} \cdot \mathrm{m}^{-1} \mathrm{~K}^{-1}$. The silver sintered joints was used for they high thermal stability and high thermal conductivity. In all structure is used one channel of LTCC layer with thickness $0.214 \mathrm{~mm}$. Inlet and outlet holes are the same for every substrate and diameter of holes are $2 \mathrm{~mm}$. The position of power chip on the substrate was selected due to need to cooling the largest area of the chip by the flow of coolant in the channels. For the investigation of the impact of the first chips' thermal load on the second chip, two chips placed on LTCC substrate were used. Fig. 2 illustrates the cross section of the structure \#4 of the cooling concepts realized by LTCC technology.

\section{SIMULATIONS}

The thermal performance of analyzed cooling methods was evaluated by the simulations in Mentor Graphics FloEFD $^{\mathrm{TM}}$ commercial simulation software. The junction temperature of the chip was simulated for a constant volume flow of coolant through the fluidic channels. For the simulation of the coolant the demineralized water with an inlet temperature of $20^{\circ} \mathrm{C}$ was used. The thermal load of the chip was selected by the maximum junction temperature which does not exceed the boiling point of the water. The thermal resistance $\left(R_{t h}\right)$ was calculated from the temperature gradient among chip junction $\left(v_{\mathrm{j}}\right)$, the inlet fluid $\left(v_{\text {iff }}\right)$ and the thermal load $(P)$ of chip (1) [5].

$R_{t h}=\frac{\vartheta_{j}-\vartheta_{i f}}{P}\left[K . W^{-1}\right]$

The thermal resistance was calculated for different volume flow rate with the range of $10 \mathrm{ml} \cdot \mathrm{min}^{-1}$ to $300 \mathrm{ml} \cdot \mathrm{min}^{-1}$.

The first type of channel (\#1) was designed with 11 curves in the shape of meander. This channel was chose for simulation and investigation of the curves' impact on the fluid's pressure inside the channels. The cooling area under one power chip in the structure $\# 1$ is $71 \mathrm{~mm}^{2}$. The difference between the structures $\# 1$ and $\# 2$ is in the number of used curves which can reduce the pressure in the channel with maintaining the effectiveness of cooling. Cooling area under one of power chip in this structure is $60 \mathrm{~mm}^{2}$.

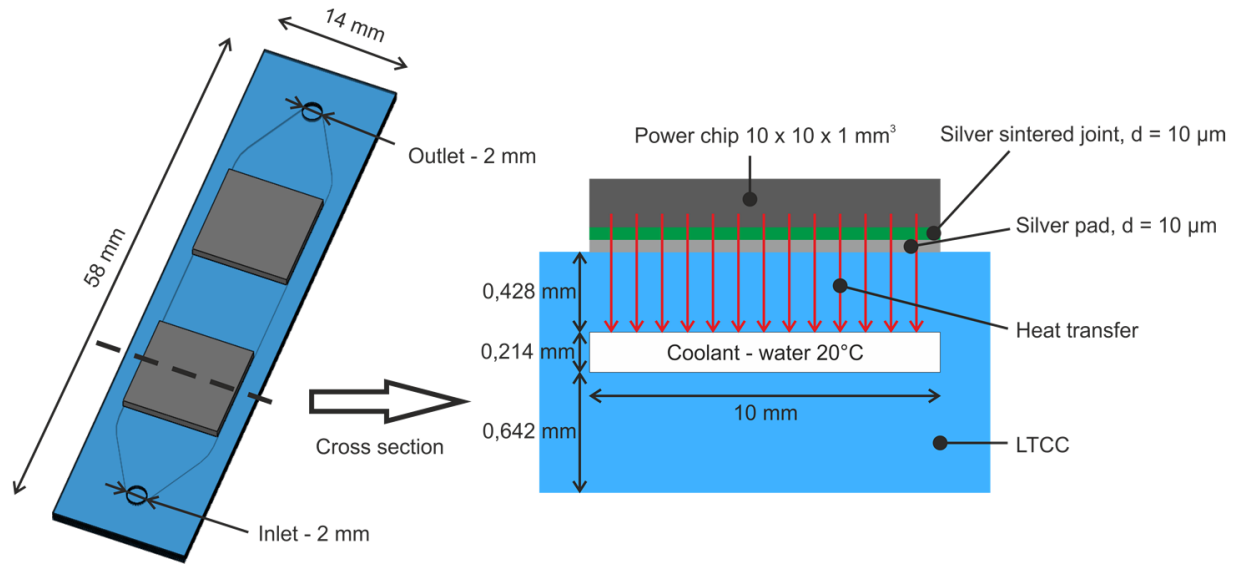

Fig. 2 Cross section of the simulation model with structure \#4 


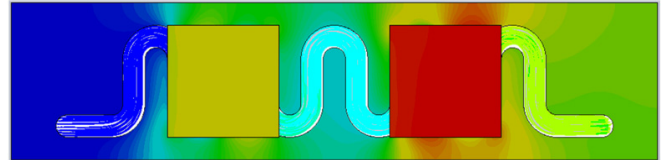

\#1

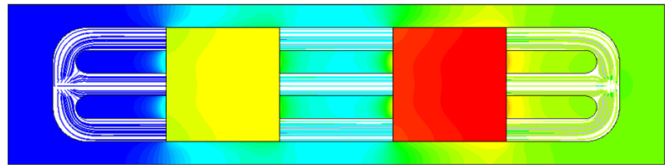

\#3

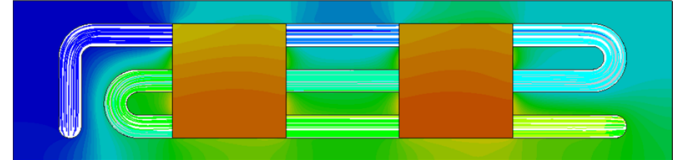

\#2

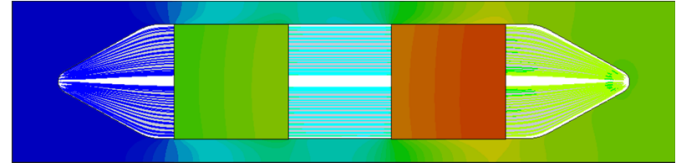

\#4

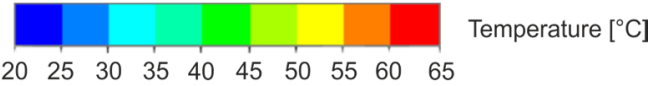

Fig. 3 Simulated temperature distribution of structure $\# 1, \# 2, \# 3$ and $\# 4$ at the thermal load of $10 \mathrm{~W}$ per chip. The volume flow is set to $10 \mathrm{ml} . \mathrm{min}-1$ and coolant fluid from left side to right.

The structure \#3 has three separate channels with a few curves such as can be seen in the Fig. 1. This structure of channel was created for the minimization of the pressure during high flow rate of water. The cooling area under the power chip is $60 \mathrm{~mm}^{2}$. The last structure \#4 has the one big channel with largest area of $100 \mathrm{~mm}^{2}$. However, the big cross section of channel provides fluently flow rate with minimum turbulence and decrease the pressure inside channel. Fig. 3 shows the simulated temperature distribution by coolant and substrate from the power chips realized by Mentor Graphics FloEFD ${ }^{\mathrm{TM}}$. It can be seen that the temperature distribution was from the left side (inlet) to right side (outlet), what was caused by fluidic coolant. The volume flow rate of coolant was set to $10 \mathrm{ml} \cdot \mathrm{min}^{-1}$. The simulations demonstrate the impact of the thermal load of first chip (left) on temperature of the second chip (right). The minimum impact is in the case of structure \#2, which can be seen in the Fig. 3 as well as in the Fig. 5.

\section{RESULTS OF SIMULATIONS AND DISCUSSION}

In the Fig. 4 the thermal resistance as a function of the volume flow rate of all 4 structures is plotted. The simulations demonstrate the design \#4 had the lowest thermal resistance. The biggest channel inside LTCC substrate reduces the thermal resistance by $2.8 \%$ in average. The structure \#2 had the worst thermal resistivity in the case of the flow rate was less than $50 \mathrm{ml} \cdot \mathrm{min}^{-1}$. It can be seen that the thermal resistance is significantly dependent on the volume flow rate. At volume flow rate lower than $50 \mathrm{ml} \cdot \mathrm{min}^{-1}$ the thermal resistance $\left(\mathrm{R}_{\mathrm{th}}\right)$ increases exponentially. On the other hand, the thermal resistance above $50 \mathrm{ml} \cdot \mathrm{min}^{-1}$ decreases slowly as it can be seen in the Fig. 4.

The pressure of coolant inside the channel is also dependent on the volume flow rate which is shown in the Fig. 4. The highest pressure (13.4 bar at $\left.300 \mathrm{ml}^{\mathrm{min}} \mathrm{m}^{-1}\right)$ was in the case of structure \#1. In the structures \#1 and \#2 the pressure increases significantly by increasing the flow rate. The lowest pressure 1.2 bar in average had the structure \#3 and \#4. These structures have almost constant pressure during all volume of flow rate.

Structure \#4 is the most promising candidate to cooling power chips on LTCC substrate for the reason of low thermal resistance at different volume flow rate as well as the simple fabrication requirements. In this structure the optimal flow rate to cooling the power chip is $150 \mathrm{ml} \cdot \mathrm{min}^{-1}$. If the volume flow rate increases above $150 \mathrm{ml} \cdot \mathrm{min}^{-1}$ the thermal resistance is relatively stable (Fig. 4). Structure \#4 gives possibility for optimal flow rate and optimal cooling effect of power chips.
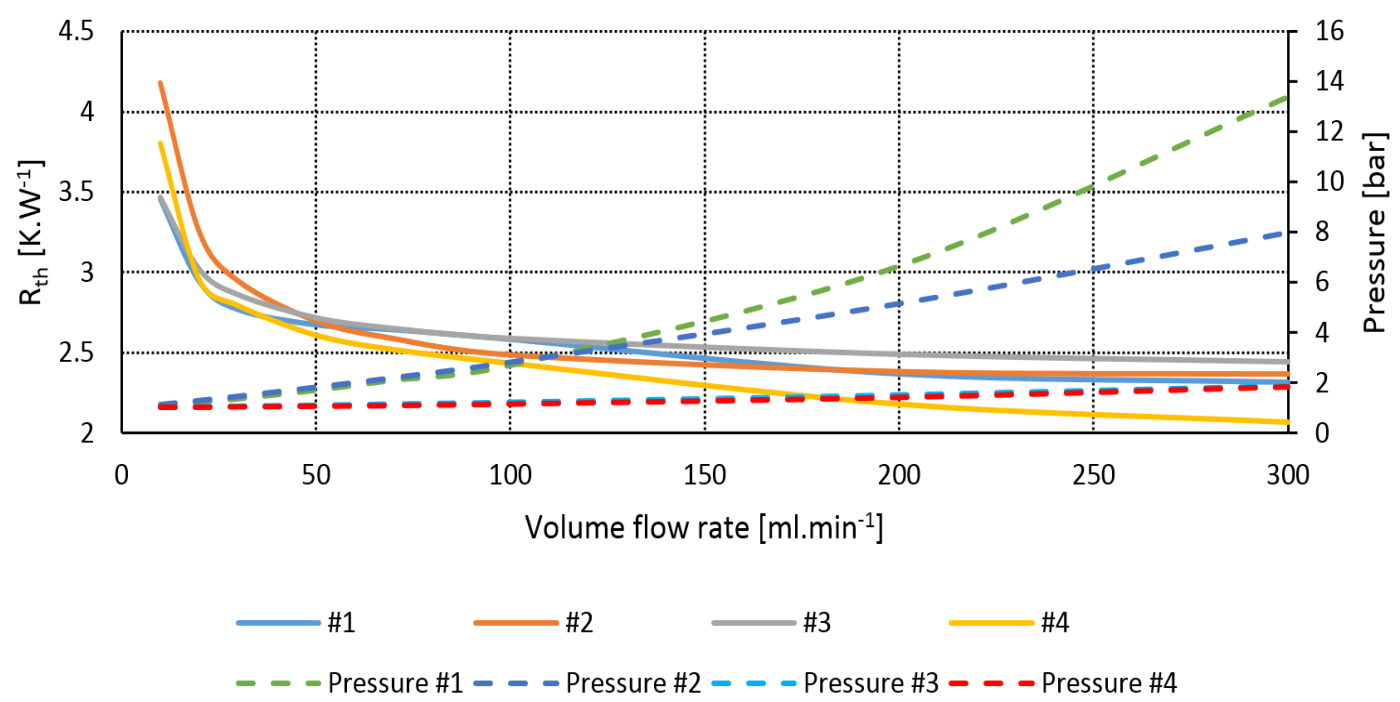

Fig. 4 The influence of volume flow rate on the thermal resistance and pressure 


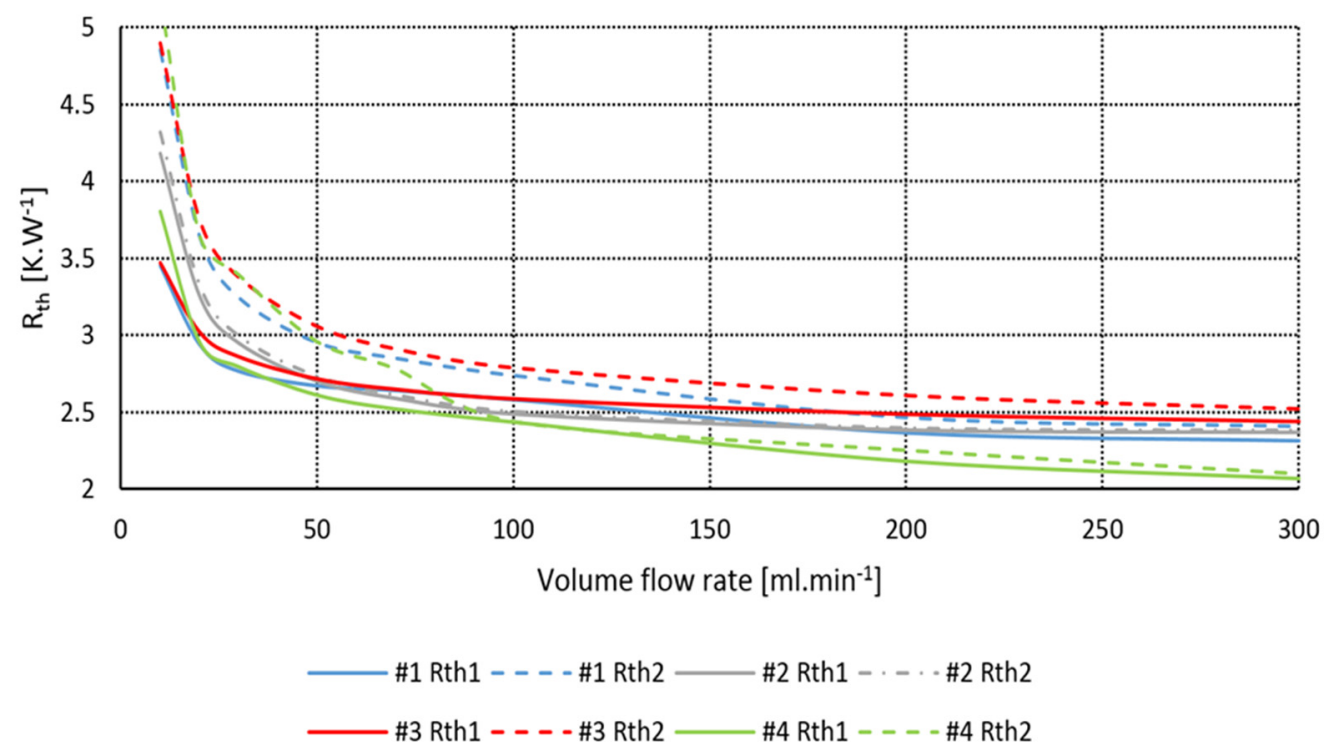

Fig. 5 The influence of volume flow rate on the thermal resistance and pressure

In the Fig. 5 the thermal resistance of both chips as a function of the volume flow rate is plotted. The simulations demonstrate the impact of the thermal load of the first chip (No. 1) on the temperature of the second chip (No. 2). The thermal resistance of substrate was different for the chips No. 1 and No. 2 in all structures. The highest difference of thermal resistance is at structure \#1, \#3 and $\# 4,16 \%$ in average. This difference was caused by direct flow of fluid from chip No. 1 to chip No. 2. At the chip No. 1 there was the transfer of the thermal energy on to chip No. 2 by the coolant in the channel. At the structure \#4 the difference of the thermal resistance is approximately $4 \%$ at optimal flow rate $150 \mathrm{ml} \cdot \mathrm{min}^{-1}$. The minimum difference of $1.3 \%$ is at the structure \#2. It is because the coolant flows from the chip No. 1 to chip No. 2 in the first step. After this the coolant continues again to the chip No. 1, which causes the balanced thermal resistance of both chips (Fig. 3).

\section{CONCLUSIONS}

The LTCC substrates with fluidic channels simulated by a Mentor Graphics FloEFD ${ }^{\mathrm{TM}}$ was presented in this paper. The influence of the channel structures on the thermal resistance and pressure of the coolant was investigated. The simulations show there is a nonlinear relation between the volume flow rate and the thermal resistance. Increasing the mass flow rate of the coolant causes the reduction of the thermal conductivity as well as causes the pressure rise inside the channels. The structures of channels have the significant impact on the coolant pressure. Substrate with structure \#4 is the most promising candidate to cooling power chips on LTCC substrate, for the reason of low thermal resistance at different volume flow rate. Structure \#4 reduces the thermal resistance by $2.8 \%$ in average by contrast to structure \#1, \#2 and \#3. LTCC structure with embedded microchannel structure \#4 decrease additional temperature of chips about $86 \%$ (at $2 \mathrm{~W}$ ) in average by contrast to LTCC substrate without cooling channels. Volume rate flow at the structure \#4 at the power loss of $10 \mathrm{~W}$ was from $10 \mathrm{ml}^{\mathrm{min}} \mathrm{m}^{-1}$ to
$300 \mathrm{ml} \cdot \mathrm{min}^{-1}$. Thermal resistance continuously decreases

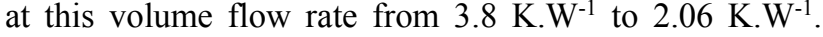
The structure of microchannel \#3 characterized in that thermal resistance at the flow rate from $50 \mathrm{ml} \cdot \mathrm{min}^{-1}$ to 300 $\mathrm{ml} \cdot \mathrm{min}^{-1}$ was nearly invariable. The structure of microchannel \#3 represents the less effective cooler.

The simulations demonstrate the impact of the thermal load of first chip (No. 1) on the temperature of the second chip (No. 2) as well as. The minimum difference $1.3 \%$ of the thermal resistance was at structure $\# 2$. At the other structures the difference of the thermal resistance was approximately $12.9 \%$ in average at the volume rate flow lower than $150 \mathrm{ml} \cdot \mathrm{min}^{-1}$.

Multilayer structure of LTCC substrate with microchannel represents new modern and effective approach to cooling systems in power electronics. The importance of this new technology is very significant in continuous miniaturisation of power modules.

\section{ACKNOWLEDGMENTS}

This work was supported by the Slovak Research and Development Agency under the contract No. APVV-140085: Development of New Generation Joints of Power Electronics Using Nonstandard Sn Based.

\section{REFERENCES}

[1] ZHANG, L. - ZHANG, Y. F. et al.: Fluid flow and heat transfer characteristics of liquid cooling microchannels in LTCC multilayered packaging substrate, International Journal of Heat and Mass Transfer, Vol. 84, 2015, pp. 339-345.

[2] HU, D. - MAO, M. et al.: Investigation of cooling performance of micro-channel structure embedded in LTCC substrate for 3D micro-system, Solid-State and Integrated Circuit Technology (ICSICT), 2012, pp. 1-3.

[3] MALECHA, K. - GOLONKA, L.: Threedimensional structuration of zero-shrinkage LTCC 
ceramics for microfluidic applications, Microelectronics Reliability, Vol. 49, No. 6, 2009, pp. 585-591.

[4] ZHANG, J. - ZHANG, Y. F. et al.: Simulation of fluid flow and heat transfer in microchannel cooling for LTCC electronic packages, Electronic Packaging Technology \& High Density Packaging, International Conference on Beijing, 2009, pp. 327330.

[5] WELKER, T. - MÜLLER, J.: Design, simulation and fabrication of liquid cooled LTCC devices utilizing integrated channels, 15th IEEE Intersociety Conference on Thermal and Thermomechanical Phenomena in Electronic Systems (ITherm), 2016.

[6] JIA, S. - MIAO, M. et al.: A 3D micro-channel cooling system embedded in LTCC packaging substrate, Nano/Micro Engineered and Molecular Systems (NEMS), 2012 7th IEEE International Conference on Kyoto, 2012, pp. 649-652.

[7] THELEMANN, T. - THUST, H. et al.: Liquid Cooled LTCC-Substrates for High Power Applications, International Microelectronics and Packaging Society, Vol. 23, 2000, pp. 209-214.

[8] PETERSON, K. A. - KNUDSON, R. T. et al.: LTCC in microelectronics, microsystems, and sensors, Mixed Design of Integrated Circuits and Systems, 2008, pp. 23-37.

[9] BARTSCH, H. - WELKER, T. et al.: LTCC based bioreactors for cell cultivation, IOP Conference Series: Materials Science and Engineering, Vol. 104, 2015.

[10] GROß, G. A. - THELEMANN, T. et al.: Fabrication and fluidic characterization of static micromixers made of low temperature cofired ceramic (LTCC), Chemical Engineering Science, Vol. 63, No. 10, 2008, pp. 2773-2784.

[11] MIAO, M. - JIN, Y. et al.: Investigation of Micromachined LTCC Functional Modules for High-density 3D SIP based on LTCC Packaging Platform, 63RD Electronic Components and Technology Conference, 2013, pp. 1815-1822.
Received February 20, 2017, accepted May 2, 2017

\section{BIOGRAPHIES}

Tomas Girasek was born on 1989. In 2014 he graduated (MSc) with distinction at the Department of Technologies in Electronics of the Faculty of Electrical Engineering and Informatics at Technical University of Košice. Now, he is a $\mathrm{PhD}$. student at the same department. His scientific research is oriented to thermal management, multilayer structures, ceramic circuits and joints in power electronics.

Alena Pietrikova is full professor (2007) of Electrotechnology and Materials at the Faculty of Electrical Engineering and Informatics Technical University of Košice, Slovak Republic. Her research work is concentrated on problems concerned with modern materials and technologies in electronics (film technologies, assembling technologies in electronics, and materials for electronics). She is an author or co-author of more than 250 research articles in international journals or conference proceedings, 5 patents and 5 books.

Tilo Welker, born in 1984, received his Diploma degree in computer engineering specialized in integrated hardand software systems 2009, from the Ilmenau University of Technology, Germany. He is a scientific coworker at the Institute of Micro- and Nanotechnologies at the Ilmenau University of Technology, Germany. Main interest of his research include thermal management, packaging, ceramic circuits and 3D integration.

Jens Müller, born September 1965, received his diploma degree for electrical engineering and the doctoral degree from Ilmenau University of Technology, Ilmenau, Germany, in 1992 and 1997 respectively. In July 2008 he was assigned full professor for the Department of Electronics Technology at the same university. His particular research interest covers functional integration for ceramic based System-in-Packages considering aspects of harsh environmental use, and high thermal / highfrequency requirements with a strong focus on LTCC materials and its combination with Silicon by a proprietary process. 